\title{
3
}

\section{Breaking the Traditional Trap: Assessing Drivers of Modern Technology Adoption by Smallholder Farmers in Hurungwe District, Zimbabwe}

\section{Carren Pindiriri}

\subsection{Introduction}

The importance of adopting modern technology in agriculture, especially in a changing climate, cannot be underestimated in Africa. Many studies (Kijima et al. 2008; Mendola 2007; Liu and Wang 2005; de Janvry and Sadoulet 2002; Xu and Jeffrey 1998) demonstrate that agricultural modernisation increases productivity. Diffusion of modern agricultural technologies also enhances sustainable development through poverty elimination (Kassie et al. 2011; Suri 2011; Duflo et al. 2008). Concurring with these researchers, Boniphace et al. (2015) identify lack of agricultural investment and insufficient usage of modern technologies as some of the factors impeding agriculture growth in Africa. Moreover, in the 2016 African Development Bank's (AfDB) strategic plan, agricultural development through improved technologies is critical in promoting one of the bank's high 5s, namely, feeding Africa. Despite its importance, the

\section{Pindiriri $(\bowtie)$}

University of Zimbabwe, Harare, Zimbabwe 
uptake of modern agricultural technologies has, however, remained very low in sub-Saharan Africa (Langat et al. 2013; Gollin et al. 2005).

For instance, Gollin et al. (2005) reveal that, in 2000, only $17 \%$ of the area planted for maize had modern maize varieties in sub-Saharan Africa compared to $57 \%$ in Latin America and the Caribbean. This low uptake of agricultural technologies is a cause for concern in Africa where food security is severely threatened by the changing climate. While the adoption of modern agricultural technologies has been identified as the main driver of green revolution in Asian countries (Ravallion and Chen 2004), it still remains a puzzle why the adoption rates of these agricultural technologies have remained low in sub-Saharan Africa (Matsumoto et al. 2013; World Bank 2008). Mkandawire and Matlosa (1994) even query why the green revolution which transformed agriculture in Asia and Europe failed to achieve similar results in sub-Saharan Africa. This suggests that the African continent has been trapped in the traditional production methods and has therefore remained the world's greatest laggard in agricultural technological growth (Boko et al. 2007).

Despite experiencing a decline, agriculture remains the backbone of the Zimbabwean economy, with maize production anchoring food security in the country. Maize is produced in all provinces of the country, but the largest share of maize output is from Mashonaland provinces. Hurungwe, in Mashonaland West, is the largest district and one of the major maizeproducing districts in the country. The district has the potential to significantly improve food security because of its favourable climatic conditions. It is therefore vital to take advantage of the district's potential in improving national maize production by enhancing farmers' productive capacity through various ways, which include the promotion of modern technologies in agriculture. It is in this view that this chapter scrutinises the drivers of modern technology adoption in Hurungwe. The main objectives of the chapter are therefore to: (1) measure the agricultural technological gap for Hurungwe farmers and (2) examine the drivers of modern agricultural technology adoption in Hurungwe. An appreciation of the drivers of technology adoption in the district helps in: (1) identifying the characteristics of adopters and predicting adoption rates, (2) identifying policy targets for improving adoption rates, (3) enhancing Sustainable Development Goals (SDGs) and (4) developing marketing strategies for new technologies (Oster and Thornton 2012). 
Although a substantial amount of work has been done on the determinants of agricultural technology adoption across the world, very little has been done in Zimbabwe. Agricultural technology adoption has generally been regarded as a very slow process whose many aspects have continued to be poorly understood (Simtowe et al. 2011 and Diagne and Demont 2007). Studies that have considered Zimbabwe in agricultural technology adoption were mainly done for sub-Saharan Africa (Muzari et al. 2012; Boko et al. 2007; Mkandawire and Matlosa 1994). These studies nevertheless fall short of proper methodological approaches to the exploration of the drivers of technology adoption in agriculture as they overlook nonexposure and selection biases prevalent in classical technology adoption models such as probit and logit applied by many researchers (Fadare et al. 2014; Hailu et al. 2014; Zivanemoyo and Mukarati 2013; Ayoola 2012).

This chapter is therefore expected to add to the list of existing literature on the drivers of modern technology adoption in agriculture. It adds new literature on agricultural technology adoption in Zimbabwe in the following ways: first, the selection of a study area which has never been investigated in the area of determinants of agricultural technology adoption helps in unmasking the cloaked. Second, focusing on a particular district with identical culture among farmers helps in avoiding misleading estimators from national-based models which provide an average coefficient for heterogeneous areas. Third, the chapter applies a non-classical adoption technique (average treatment effects) to remedy the problems resulting from nonexposure and selection biases. Despite being used in a number of countries (Simtowe et al. 2011; Diagne and Demont 2007), the average treatment effects (ATE) technique has never been applied to study the determinants of technology adoption by famers in Zimbabwe. The chapter therefore extends the application of this technique to Zimbabwean farmers.

\subsection{Literature Survey}

The technology adoption curve has for long been regarded by sociologists and marketers as a normative and descriptive model to decision-making just like the product life cycle (Anderson and Zeithaml 1984; Midgley 1977; Rogers 1962). Adopting a new technology in the traditional school 
is associated with different categories of adopters, some being innovators (immediate adopters of a new technology) and others being laggards (last group to adopt a new technology). The product life cycle theory, thus, regards young people as innovators and early adopters while the elderly are regarded as laggards. From the 1980s, researchers began to question the applicability of the traditional product life cycle because of its rigid assumption regarding the ' $S$ ' shape which could not match empirical data in many cases. In this view, researchers such as Lambkin and Day (1989), Bayus (1988) started to extend the traditional product life cycle through diffusion models. Foster and Rosenzweig (2010) argue that a farmer makes a decision to adopt technology if the technology is expected to stay profitable and if it is available and affordable. In this context of profit maximisation, Sunding and Zilberman (2000) and Pingali et al. (1987) further demonstrate how farm size restricts technology adoption in a profit-maximising problem. However, farmers may choose to adopt a technology in anticipation of future benefits even if it is not currently profitable (Smale et al. 1995).

Many studies have, however, been done to investigate the factors explaining agricultural technology adoption rates despite having scanty literature in Zimbabwe. Plenty of literature on agricultural technology adoption is available in many countries, with developing countries recently contributing a significant share of the literature (Diagne and Demont 2007). These empirical findings reveal that adoption of agricultural technologies relies on farmers' perceptions about the technology (Rogers 1962) and further classify drivers of technology adoption into farmers' socio-demographic factors, institutional forces and farmers' economic status (Doss et al. 2003). In some cases, drivers of agricultural technology adoption have been categorised as market motivations (profit and risk), bio-physical drivers and farmers' preferences (Pattanayak et al. 2003). Technology adoption has been defined either as continuous or discrete variable in these studies (Doss et al. 2003). However, in many cases it has been considered as a discrete variable because of the complexities involved when measuring it as a continuous variable, especially in African agriculture where farmers rarely keep records of input purchases. The evidence produced by Pattanayak et al. 2003 meta-analysis indicates that over $95 \%$ of the 32 reviewed studies on agro-forestry technology 
adoption have measured technology adoption as a discrete variable and applied either the probit, logit or linear probability models.

Many more studies on agricultural technology adoption have applied discrete dependent variable models and identified the following drivers: age of the farmer, farm size, exposure to technology, access to credit, farmer's education, access to extension services, gender, household size, income, farming experience, neighbourhood, climatic conditions and agricultural training among others (Boniphace et al. 2015; Fadare et al. 2014; Hailu et al. 2014; Langat et al. 2013; Uaiene et al. 2009; Dimara and Skuras 2003). Although there is general consensus among the researchers with regard to the effect of all the other identified factors on technology adoption, the effect of farm size on the farmer's decision to adopt modern technology has remained unsettled. Akudugu et al. (2012) argue that the effect of farm size on adoption of agricultural technologies can either be positive, harmful or impartial. For example, Langat et al. (2013), Uaiene et al. (2009) and Feder et al. (1985) established a positive association between farm size and technology adoption while Harper et al. (1990) found farm size to have a negative effect on agricultural technology adoption. Other studies even established a neutral relationship between farm size and technology adoption (Fadare et al. 2014; Reimer and Fisher 2014).

Despite its extensive nature, literature on drivers of technology adoption in agriculture has its own drawbacks. First, a majority of the studies mainly focussed on drivers of adoption of hybrid seeds (Boniphace et al. 2015; Fadare et al. 2014; Langat et al. 2013; Zivanemoyo and Mukarati 2013; Simtowe et al. 2011) while overlooking farm mechanisation. Only few studies, for example, Akudugu et al. (2012), Uaiene et al. (2009) and Dimara and Skuras (2003) considered farm mechanisation as an equally important type of technology adoption worth to be investigated in farming households. The transformation of communal farmers from subsistence entities into business entities through modernisation of agricultural production systems is essential for improving food security in Africa. An investigation of the determinants of farm mechanisation is therefore critical in the African continent where most of the smallholder farmers are trapped in the traditional production systems. 
Second, most of the studies (over 95\%) have applied the classical adoption models, namely logit and probit. In most cases, the estimated parameters of these models tend to underestimate the true population parameters of adoption determinants due to selection and non-exposure biases inherent in discrete adoption models (Diagne and Demont 2007). Very few researchers have, however, recently turned their attention to the use of methods that remedy these biases. For example, Simtowe et al. (2011) applied a programme evaluation technique to investigate the determinants of adoption of improved Pigeon pea varieties in Tanzania. The use of improved methodologies helps in avoiding misleading policy recommendations.

Third, despite being one of the major maize-producing countries in Africa, no attempt has been made to empirically examine drivers of technology adoption by maize farmers in Zimbabwe. This is a huge motivation for this study. Hurungwe District has excellent climatic conditions for maize production and remains the main maize-producing district in Zimbabwe. Modernisation of agriculture in the district will go a long way in feeding Zimbabwe and other sub-Saharan African countries.

\subsection{Methodology and Data Issues}

Classical economists argue that farmers can only adopt new technology if they are exposed to it (Foster and Rosenzweig 2010). Awareness is therefore a necessary condition for adopting a new technology. However, when a new technology is introduced, farmers may not be universally exposed to it, as a result the observed sample parameter may not be a consistent estimator for the true population parameter. Diagne and Demont (2007) argue that applying classical models of adoption when the target population is not universally exposed to the new technology may result in a nonexposure bias which produces biased and inconsistent estimators for population adoption rates. In addition, Simtowe et al. (2011) show that farmers' exposure to a new technology is non-random since extension workers may target farmers with higher probability of adopting or farmers may get exposed through their self-interests. Exposure to a new technology therefore suffers from selection bias signifying a non-linear association between exposure to and adoption of a new technology. It is against this 
background that this chapter evaluated the drivers of technology adoption using a programme evaluation methodological approach as in Wooldridge (2002), Diagne and Demont (2007) and Simtowe et al. (2011).

Consider $i$ as indexing farmers and $\boldsymbol{E}_{\boldsymbol{i}}$ as a treatment indicator, equal to 1 if the farmer is exposed to agricultural technology, that is, if the farmer is treated and equal to 0 if the farmer is not exposed to agricultural technology (not treated). Farmers exposed to agricultural technology were referred to as the 'treated' while those not exposed to technology were the 'untreated'. A farmer was said to have adopted modern agricultural technology if he/she had adopted at least one of the following as an independent farmer: hybrid or improved seed variety, a tractor, a pump, a harvester, a planter, a generator, modern irrigation equipment or modern weather forecasting equipment. Further, consider $\boldsymbol{\pi}_{i 0}$ and $\boldsymbol{\pi}_{i 1}$ to be the potential adoption outcomes that would occur when a farmer is not treated $\left(\boldsymbol{E}_{\boldsymbol{i}}=0\right)$ and when a farmer is treated $\left(\boldsymbol{E}_{\boldsymbol{i}}=1\right)$, respectively. Either $\boldsymbol{\pi}_{i 0}$ or $\boldsymbol{\pi}_{\boldsymbol{i} 1}$ is observable but not both. For example, we can only observe that an untreated farmer has not adopted agricultural technology but we cannot certainly deduce what would have been the outcome if this farmer was exposed to the technology. The inference is therefore counterfactual, an adoption outcome that would have happened if the farmer was exposed to technology. In other words, the impact of exposure on technology adoption on the same farmer cannot be measured and this is referred to as the problem of missing data (Dimara and Skuras 2003).

The agricultural technology adoption outcome for the $i$ th farmer was therefore given as:

$$
\pi_{i}=\boldsymbol{E}_{i} \pi_{i 1}+\left(1-\boldsymbol{E}_{i}\right) \pi_{i 0}
$$

Equation (3.1) can equally be expressed as:

$$
\pi_{i}=\pi_{i 0}+\left(\pi_{i 1}-\pi_{i 0}\right) E_{i}=\alpha_{i}+\beta_{i} E_{i}
$$

where $\boldsymbol{\alpha}_{i}=\boldsymbol{\pi}_{i 0}$ and $\boldsymbol{\beta}_{i}=\boldsymbol{\pi}_{i 1}-\boldsymbol{\pi}_{i 0}$ are the intercept and the treatment effect for the $i$ th farmer, respectively. Since only one of the components of $\boldsymbol{\beta}_{\boldsymbol{i}}$ is observable, the treatment effect $\left(\boldsymbol{\beta}_{i}\right)$ is unidentified but we can identify 
useful measures namely: (1) ATE which averages the entire population of the farmer treatment effects or averages $\boldsymbol{\beta}_{\boldsymbol{i}}$ over all the sampled farmers, (2) the average adoption outcome of the treated or farmers exposed to technology (ATET) which averages $\boldsymbol{\beta}_{\boldsymbol{i}}$ over a sub-set of farmers exposed to technology and (3) the average adoption outcome of the untreated farmers (ATENT) which averages $\boldsymbol{\beta}_{\boldsymbol{i}}$ over a sub-set of farmers not exposed to technology. The three measures of treatment effect are measured as:

$$
\begin{gathered}
\operatorname{ATE}=E\left(\beta_{\mathbf{i}}\right)=E\left(\pi_{\mathbf{i} 1}-\pi_{\mathbf{i} 0}\right)=\beta=E\left(\pi_{1}-\pi_{0}\right) \\
\operatorname{ATET}=E\left[\boldsymbol{\beta}_{i} \mid \boldsymbol{E}_{i}=1\right]=E\left[\left(\pi_{i 1}-\pi_{i 0}\right) \mid \boldsymbol{E}_{i}=1\right] \\
\mathrm{ATENT}=E\left[\beta_{i} \mid \boldsymbol{E}_{i}=0\right]=E\left[\left(\pi_{i 1}-\pi_{i 0}\right) \mid \boldsymbol{E}_{i}=0\right]
\end{gathered}
$$

Since exposure to technology is usually a necessary condition for technology adoption, it implies that $\boldsymbol{\pi}_{\boldsymbol{o}}=0$ and ATE $=E\left(\boldsymbol{\pi}_{\boldsymbol{1}}\right)$. The difference between ATE and ATET is called the population selection bias (Wooldridge 2002). In order to produce unbiased and consistent estimators for ATE and ATET, there is need to control for this population selection bias (Diagne and Demont 2007). Farmers who adopt agricultural technologies become exposed to those technologies, hence, the need to correct the likely problem of endogeneity where exposure to technology is also determined within the system. An endogenous treatment of binary outcomes was hence applied in this chapter.

Variables used in this chapter came from the reviewed literature. The two endogenous binary variables are (1) agricultural technology adoption $(\boldsymbol{\pi})$ by a farmer which took a value of 1 if the farmer had adopted any agricultural technology (either mechanisation or hybrid seeds) as an independent farmer and 0 otherwise and (2) farmer's exposure to agricultural technologies $(\boldsymbol{E})$ which took a value of 1 if the farmer was exposed to any agricultural technology and zero otherwise. The modern technologies considered in this chapter include (1) mechanical which consists of tractors, harvesters, planters, irrigation equipment such as water pumps and generators and (2) biological and geographical which consist of improved seed varieties and forecasting methods. The two endogenous variables, $\boldsymbol{\pi}$ and $\boldsymbol{E}$, are determined by vectors of covariates, $\boldsymbol{X}$ and $\boldsymbol{Z}$, 
respectively. In summary, technology adoption and its drivers can be estimated from random vectors, $\left(\boldsymbol{\pi}_{\boldsymbol{i}}, \boldsymbol{E}_{\boldsymbol{i}}, \boldsymbol{X}_{\boldsymbol{i}}, \boldsymbol{Z}_{i}\right)$ for $i=1 \ldots n$. In order to estimate ATE, the treatment condition $(\boldsymbol{E})$ is assumed to be independent of the possible adoption outcomes, $\boldsymbol{\pi}_{\mathbf{0}}$ and $\boldsymbol{\pi}_{\mathbf{1}}$, conditional on a vector of covariates $\boldsymbol{Z}$ that explain exposure, that is, $\operatorname{Prob}\left[\boldsymbol{\pi}_{s}=1 \mid \boldsymbol{E}\right.$, $Z]=\operatorname{Prob}\left[\boldsymbol{\pi}_{s}=1 \mid Z\right]$ for $s=0,1$. This is referred to as the conditional independence axiom (Wooldridge 2002). The population mean technology adoption conditional on vector $\boldsymbol{X}$ is given as:

$$
\operatorname{ATE}(\boldsymbol{X})=E\left[\pi_{1}=1 \mid \boldsymbol{X}\right]
$$

One way of estimating the ATE parameters is to interact $\boldsymbol{E}$ with covariates and then apply the usual parametric regression-based approaches. The second way, which was used in this chapter, is the application of a two-stage estimation technique. First, a propensity score was generated through regressing treatment, $\boldsymbol{E}$, on its covariates vector, $\boldsymbol{Z}$, that is, $\operatorname{Prob}[\boldsymbol{E}=1 \mid Z]=\operatorname{Prob}(Z)$. Second, ATE was estimated by parametric techniques. With non-parametric approach, the conditional independence assumption is extended to include the independence of possible adoption from the drivers of treatment $(Z)$ conditional on vector $\boldsymbol{X}$, that is, $\operatorname{Prob}\left[\boldsymbol{\pi}_{\boldsymbol{1}}=1 \mid \boldsymbol{X}, \boldsymbol{Z}\right]=\operatorname{Prob}\left[\boldsymbol{\pi}_{\boldsymbol{1}}=1 \mid \boldsymbol{X}\right]$. When using the parametric approach as done in this chapter, the conditional independence assumption allows us to estimate technology adoption and its drivers from the treated sub-sample only through the following specification:

$$
E[\pi \mid \boldsymbol{X}, \boldsymbol{E}=1]=f(\boldsymbol{X}, \boldsymbol{\lambda})
$$

where $f$ is an identified linear or non-linear function of a vector of explanatory variables $\boldsymbol{X}$ and unknown parameter vector $\lambda$ to be estimated. The estimated equation was then used to compute the predicted values which were then used to estimate the ATE and ATET for the whole sample and treated sub-sample, respectively. The farmers' technology adoption gap (GAP) is the deviation of ATE from the joint exposure and adoption parameter (JEA). 
Technology adoption literature identifies many factors explaining farmers' decision to adopt new technologies and their exposure to agricultural technologies. Table 3.1 provides a summary of the determinants of exposure to and adoption of agricultural technologies, that is, the variables in vectors $Z$ and $X$. The variables, age (in years), farm size (in hectares), extension services (number of contacts per year), income (dollars), farming experience (in years), education (in completed years), urbanity (in years), household size (number of members) and bread winner urbanity (in years) were measured as continuous variables while the rest were measured as dichotomous variables (see Table 3.1).

The data used in this chapter were collected using a questionnaire from a sample of 411 farmers subjected to an experiment in Hurungwe. A multistage sampling procedure was carried out. First, wards were stratified according to ecological zones and one ward was then randomly selected from each ecological zone (regions IIA, III and IV). Only ecological region $\mathrm{V}$ was disregarded because the region is set aside for wildlife management. Each selected ward was proportionally represented in terms of the sampling units. Enumeration areas (EAs), as demarcated by the Zimbabwe Statistical Agency (Zimstat) in 2012, within each ward, were then randomly selected and a census was carried out within the selected six EAs. Farmers not exposed to technology were considered to constitute a control group.

Table 3.1 Determinants of exposure and technology adoption

\begin{tabular}{llll}
\hline & Expected & & Expected \\
Adoption determinants $(X)$ & sign & Exposure determinants $(Z)$ & sign \\
\hline Exposure to technology $(E)$ & + & Extension services & + \\
Age of the farmer & $+/-$ & Age of the farmer & $+/-$ \\
Farm size & $+/-$ & Farmer's education & + \\
Credit (=1 for access to) & + & Urbanity & + \\
Farmer's education & + & Gender (=1 for male) & + \\
Extension services & + & Training (=1 for trained) & + \\
Gender (=1 for male) & + & Knowledge source & + \\
Belief (=1 for traditional) & - & Farmer's experience & + \\
Income & + & & \\
Farming experience & + & & \\
Weather (=1 for wet) & + & & \\
Perception (=1 for + ve) & + & & \\
Training (=1 for agricultural & + & & \\
$\quad$ trained) & & & \\
Parent belief (1 if tradition) & - & & \\
\hline
\end{tabular}




\subsection{Results and Discussion}

The findings show that $76.9 \%$ of the interviewed farmers were male and $80.3 \%$ were exposed to at least one type of agricultural technology. Despite many farmers being exposed to agricultural technologies in the district, only $30.2 \%$ of the farmers adopted modern agricultural technologies. Table 3.3 presents descriptive statistics of the sampled farmers categorised according to their adoption status of agricultural technologies. The statistics demonstrate that the difference between the proportion of adopters and the proportion of non-adopters in wet ecological zones and dry zones is statistically insignificant. Similarly, the difference between the average farm size of adopters and that of non-adopters is statistically insignificant.

The statistics, however, display significant differences between adopters and non-adopters in terms of gender representation, education, beliefs, credit access, technology exposure, technologies perceptions, knowledge sources, parents' beliefs, age, extension contacts, farming experience and incomes. The male to female ratio is bigger in the subsample of farmers who adopted agricultural technologies. With regard to age, the statistics in Table 3.3 concur with the theoretical supposition that when a new technology is introduced, older farmers take time to adopt it as they are reluctant to disturb their tradition. The average age in the adopters' category ( 41 years) is significantly less than the average age of non-adopters ( 45 years). Similarly, the average farming experience for adopters (14 years) is smaller than that of non-adopters (17 years). The proportion of farmers who believe in tradition is bigger in the nonadopters' sub-sample than in the adopters'. Furthermore, the statistics show an ordinarily larger percentage of farmers in the non-adopters subsample whose parents were traditionalists. In concurrence with the larger proportion of traditionalists in the non-adopters' group, the percentage of farmers who perceive modern technology to be better than traditional technologies is larger in the adopters' sub-sample. These statistics, generally, point to an important implication that farmers who are bonded to their tradition find it difficult to adopt modern technologies.

The statistics in Table 3.2 indicate that average education is significantly higher for adopters (11 years) than for non-adopters (8 years). Similarly, the percentage of agriculturally trained farmers is larger in the 
Table 3.2 Farmers' characteristics according to their adoption status

\begin{tabular}{|c|c|c|c|c|}
\hline Characteristic & $\begin{array}{l}\text { Adopters } \\
(N=124)\end{array}$ & $\begin{array}{l}\text { Non-adopters } \\
(N=287)\end{array}$ & $\begin{array}{l}\text { Total } \\
(N=411)\end{array}$ & Difference \\
\hline Proportion of male farmers (\%) & 87.1 & 72.3 & 76.9 & $14.6 * * *$ \\
\hline $\begin{array}{l}\text { Proportion of farmers in wet } \\
\text { zones }(\%)\end{array}$ & 62.1 & 56.4 & 58.2 & 5.7 \\
\hline Proportion of traditionalists (\%) & 35.5 & 62.0 & 54.0 & $-26.5^{* * *}$ \\
\hline $\begin{array}{l}\text { Proportion of agric trained } \\
\text { farmers }(\%)\end{array}$ & 33.9 & 2.8 & 12.2 & $31.1 * * *$ \\
\hline $\begin{array}{l}\text { Proportion of farmers with } \\
\text { credit access }(\%)\end{array}$ & 75.8 & 15.7 & 33.8 & $60.1 * * *$ \\
\hline $\begin{array}{l}\text { Farmers exposed to modern } \\
\text { technology }(\%)\end{array}$ & 89.5 & 76.3 & 80.3 & $13.2 * * *$ \\
\hline $\begin{array}{l}\text { Farmers saying modern tech } \\
\text { is better }(\%)\end{array}$ & 98.4 & 54.4 & 67.6 & $44.0 * * *$ \\
\hline $\begin{array}{l}\text { Farmers with traditional } \\
\text { parents }(\%)\end{array}$ & 47.6 & 80.1 & 70.3 & $-32.6 * * *$ \\
\hline $\begin{array}{l}\text { Farmers with modern } \\
\text { knowledge sources (\%) }\end{array}$ & 79.0 & 22.3 & 39.4 & $56.7 * * *$ \\
\hline Average farm size (hectares) & 8.70 & 8.76 & 8.74 & -0.1 \\
\hline Average age of farmers (years) & 41.0 & 45.0 & 44.0 & $-4.0 * * *$ \\
\hline $\begin{array}{l}\text { Average education of farmers } \\
\text { (years) }\end{array}$ & 11.0 & 8.0 & 9.0 & $3.0 * * *$ \\
\hline $\begin{array}{l}\text { Average extension contacts } \\
\text { (number per year) }\end{array}$ & 15.0 & 6.0 & 10.0 & $9.0 * * *$ \\
\hline $\begin{array}{l}\text { Average farming experience } \\
\text { (years) }\end{array}$ & 14.0 & 17.0 & 16.0 & $-3.0 * *$ \\
\hline Average yearly income (dollars) & 6407 & 1654 & 3088 & $4753 * * *$ \\
\hline
\end{tabular}

$* * *, * *$ and * indicate that the difference between adopters and non-adopters is statistically significant at $1 \%, 5 \%$ and $10 \%$ level, respectively

adopters' category. Although the findings show that only $12.2 \%$ of farmers were agriculturally trained, $33.9 \%$ of the adopters were agriculturally trained and only $2.8 \%$ of the non-adopters were agriculturally trained. Moreover, the average extension contact visits for adopters are significantly more than that of non-adopters. Increased extension visits are associated with increased farmer education, hence increased exposure to agricultural technologies. Likewise, $79 \%$ of the adopters have access to modern knowledge sources compared to only $22.3 \%$ of the non-adopters. These findings suggest a positive association between education and the decision to adopt agricultural technologies. Although access to credit 
among farmers is low (33.8\%), the difference between adopters and nonadopters is statistically significant, a contradiction to Simtowe et al. (2011) findings. About $75.8 \%$ of the adopters had access to credit while only $15.7 \%$ of the non-adopters had access to credit. The average income of adopters was significantly larger than that of non-adopters. This implies a positive association between technology adoption and exposure to technology, access to credit and income.

The findings from probit regressions presented in Table 3.3 show that only extension contacts and urbanity of the farmer explain awareness of agricultural technologies in Hurungwe District. The coefficients of the two variables are statistically significant at $10 \%$ level. The three probit models presented in columns (1)-(3) show a high degree of consistence of the factors explaining farmers' exposure to agricultural technologies. In all models, an increase in the number of extension contacts and urban experience increase the probability of the farmer's exposure to agricultural technologies. The main implication of this finding is that intensifying extension services in smallholder farms will improve farmers' awareness to improved agricultural technologies. Similar findings were established by Hailu et al. (2014) and Simtowe et al. (2011).

Table 3.3 Determinants of the probability of exposure to agricultural technologies

\begin{tabular}{llll}
\hline & $(1)$ & $(2)$ & $(3)$ \\
\cline { 2 - 4 } Variables & Exposure & Exposure & Exposure \\
\hline Gender of farmer & 0.248 & 0.239 & 0.258 \\
& $(0.189)$ & $(0.187)$ & $(0.177)$ \\
Education of farmer & 0.0158 & 0.00932 & 0.00622 \\
& $(0.0177)$ & $(0.0205)$ & $(0.0178)$ \\
Farmer's experience & $0.00939^{*}$ & 0.00290 & \\
& $(0.00555)$ & $(0.00956)$ & \\
Urbanity & $0.0325^{* *}$ & $0.0279^{*}$ & $0.0272^{*}$ \\
& $(0.0158)$ & $(0.0168)$ & $(0.0166)$ \\
Extension & $0.0272^{*}$ & $0.0286^{*}$ & $0.0289^{*}$ \\
& $(0.0155)$ & $(0.0155)$ & $(0.0154)$ \\
Age & & 0.00451 & $0.00594^{*}$ \\
& & $(0.00574)$ & $(0.00331)$ \\
Wald Chi-square & $143^{* * *}$ & $145.7^{* * *}$ & $145.9^{* * *}$ \\
Observations & 411 & 411 & 411 \\
\hline
\end{tabular}

Standard errors in parentheses

$* * * p<0.01, * * p<0.05, * p<0.1$ 
Table 3.4 Summary of adoption rates of agricultural technologies in Hurungwe

Adoption is the dependent variable

\begin{tabular}{llll}
\hline Variable & Coefficient & PO means & Coefficient \\
\hline ATE (exposure 1 vs. 0) & $0.429^{* * *}$ & PO mean (exposure 0) & $0.032^{* * *}$ \\
ATET (exposure 1 vs. 0) & $0.330^{* * *}$ & PO mean (exposure 0) & 0.000 \\
PO mean (exposure 1) & $0.460^{* * *}$ & PO mean (exposure 0) & $0.032^{* * *}$ \\
\hline
\end{tabular}

PO stands for potential outcome. $* * *, * *$ and * indicate that the coefficient is statistically significant at 1,5 and $10 \%$ level, respectively

The results presented in Table 3.4 reveal that exposure to technology causes adoption rates of agricultural technologies to increase by an average of $42.9 \%$ from the average of $3.2 \%$ of farmers not exposed to technologies. This is referred to as the ATE. The findings further show that among the exposed farmers, exposure causes adoption rates to increase by an average of $33 \%$ from the average of $0 \%$ that would have occurred if the farmers had not been exposed to agricultural technologies. This is the ATET. Potential outcome (PO) means indicate that the average rate of adoption for exposed farmers is $46 \%$ while for non-exposed farmers is only $3.2 \%$. The actual adoption rate is $30.2 \%$ and the population adoption gap emanating from farmers' incomplete exposure to agricultural technologies is $12.7 \%$. There is potential to improve adoption rates of agricultural technologies by $12.7 \%$ in Hurungwe through making farmers aware of the existing technologies. The population selection bias measured by the difference between ATE and ATET was found to be $9.9 \%$ and statistically significant at $1 \%$ level. The statistically significant selection bias demonstrates that the probability of technology adoption for a farmer in the treated group is different from the probability of technology adoption for a farmer randomly selected from the population. This therefore justifies the application of treatment effects in this chapter.

A two-step estimation technique was applied to a probit model with treatment effects in examining the drivers of agricultural technology adoption in Hurungwe. The estimated models are presented in Table 3.5 from column (1) to column (3). Coefficients which are statistically significant in the first model (column 1) remain statistically significant in the other two models signifying a reasonable degree of reliability. The findings show that factors which include education of the farmer, agricultural training, access to credit, per capita income, perception about 
Table 3.5 Drivers of technology adoption from a two-step treatment effects probit model

\begin{tabular}{|c|c|c|c|}
\hline & (1) & $(2)$ & (3) \\
\hline Variables & Adoption & Adoption & Adoption \\
\hline Age & $\begin{array}{c}0.00001 \\
(0.00274)\end{array}$ & & \\
\hline Gender (1 for males) & $\begin{array}{c}-0.029 \\
(0.054)\end{array}$ & & \\
\hline Education & $\begin{array}{l}0.014 * * \\
(0.007)\end{array}$ & $\begin{array}{c}0.012 * \\
(0.007)\end{array}$ & $\begin{array}{c}0.011 * \\
(0.006)\end{array}$ \\
\hline Experience & $\begin{array}{c}0.003 \\
(0.003)\end{array}$ & $\begin{array}{c}0.002 \\
(0.002)\end{array}$ & $\begin{array}{c}0.002 \\
(0.002)\end{array}$ \\
\hline Training ( 1 for agriculturally trained) & $\begin{array}{l}0.161 * * \\
(0.072)\end{array}$ & $\begin{array}{l}0.161 * * \\
(0.075)\end{array}$ & $\begin{array}{l}0.164^{* *} \\
(0.071)\end{array}$ \\
\hline Extension & $\begin{array}{c}0.0002 \\
(0.0011)\end{array}$ & $\begin{array}{c}0.0002 \\
(0.0011)\end{array}$ & \\
\hline Credit ( 1 for farmers with credit access) & $\begin{array}{l}0.326 * * * \\
(0.044)\end{array}$ & $\begin{array}{l}0.326 * * * \\
(0.043)\end{array}$ & $\begin{array}{l}0.308 * * * \\
(0.043)\end{array}$ \\
\hline Farm size & $\begin{array}{c}-0.0008 \\
(0.0031)\end{array}$ & $\begin{array}{c}-0.0004 \\
(0.0031)\end{array}$ & \\
\hline Per capita income & $\begin{array}{l}0.001 * * * \\
(0.0003)\end{array}$ & $\begin{array}{l}0.001 * * * \\
(0.0002)\end{array}$ & $\begin{array}{l}0.001 * * * \\
(0.0002)\end{array}$ \\
\hline Perception ( 1 for modern believers) & $\begin{array}{l}0.166 * * * \\
(0.0422)\end{array}$ & $\begin{array}{l}0.166 * * * \\
(0.0420)\end{array}$ & $\begin{array}{l}0.158 * * * \\
(0.0416)\end{array}$ \\
\hline Parent belief ( 1 for traditional parents) & $\begin{array}{l}-0.107 * * * \\
(0.040)\end{array}$ & $\begin{array}{l}-0.108 * * * \\
(0.040)\end{array}$ & $\begin{array}{c}-0.100 * * * \\
(0.0386)\end{array}$ \\
\hline Constant & $\begin{array}{c}-0.549 * * \\
(0.235)\end{array}$ & $\begin{array}{c}-0.598 * * \\
(0.237)\end{array}$ & $\begin{array}{c}-0.425^{*} \\
(0.225)\end{array}$ \\
\hline Wald Chi-square & $330.7 * * *$ & $316.2 * * *$ & $346 * * *$ \\
\hline Observations & 409 & 409 & 409 \\
\hline
\end{tabular}

Standard errors in parentheses

$* * * p<0.01, * * p<0.05, * p<0.1$

modern technologies and beliefs of farmer's parents explain farmers' decision to adopt modern agricultural technologies. The coefficients of these factors were found to be statistically significant at $10 \%, 5 \%$ or $1 \%$ level. While a number of studies (Hailu et al. 2014; Langat et al. 2013; Akudugu et al. 2012; Uaiene et al. 2009) established an association between a farmer's decision to adopt modern technology and his/her age, sex, experience, belief, extension services and farm size, this chapter established otherwise. Findings in this study are however in line with Simtowe et al. (2011) who found no association between adoption of 
improved Pigeon pea varieties and age and gender of farmers in Tanzania. Uaiene et al. (2009) also found no association between farm size and adoption of mechanical agricultural technologies in Mozambique.

Education of the farmer and agricultural training are positively associated with the probability of technology adoption. Improved education and training increase the farmer's propensity to adopt agricultural technologies by $1 \%$ and $16 \%$, respectively. Formal specialised training in agriculture has more impact on farmers' decision to adopt modern technologies compared to just formal education. Similar findings were established by Boniphace et al. (2015) in Tanzania, Kassie et al. (2011) and Kijima et al. (2008) in Uganda and Fadare et al. (2014) in Nigeria. The main implication of this finding is that increased education and training of smallholder farmers can improve adoption rates of agricultural technologies, hence improving food security for many African countries. Whereas education and training increase the farmer's probability to adopt agricultural technologies, bondage in tradition has a negative influence on farmers' decisions to adopt modern technologies. Farmers with traditionally bonded parents have more than $10 \%$ lower probability of adopting modern agricultural technologies. This is also buttressed by the effect of perception on technology adoption. Farmers who perceive modern technologies as better that traditional technologies have a $16 \%$ to $17 \%$ higher propensity to adopt modern technologies in agriculture.

The results further show that increased incomes and access to credit increase the farmer's probability to adopt modern technologies by $0.1 \%$ and $30-33 \%$, respectively. Affordability of a given technology is critical when a farmer makes the final decision on whether to adopt a given technology or not. Hailu et al. (2014) and Uaiene et al. (2009) established similar results in Northern Ethiopia and Mozambique, respectively. In concurrence with these studies, Feder et al. (1985) argue that credit access constraints are often cited as the main reason why farmers fail to adopt modern agricultural technologies. Agricultural equipment is quite expensive to most smallholder farmers and in this regard access to credit becomes crucial in the technology adoption decision-making process. As argued by Feder et al. (1985), insufficient accumulated savings by smallholder farmers prevent them from investing in modern agricultural technologies; hence, availability and access to credit may close this gap. 


\subsection{Conclusion and Policy Implications}

This study measured the agricultural technology gap and examined the drivers of modern technology adoption by maize farmers in Hurungwe, Zimbabwe. The study findings verify the presence of sample selection bias, hence the importance of using treatment effects. ATE results demonstrate that exposure to technology causes adoption rates of agricultural technologies to increase by an average of $42.9 \%$ from the average of $3.2 \%$ of farmers not exposed to technologies. The ATET findings further show that among the exposed farmers, exposure causes adoption rates to increase by an average of $33 \%$ from the average of $0 \%$ that would have occurred if the farmers had not been exposed to agricultural technologies. The population technology adoption gap caused by non-exposure of farmers to agricultural technologies in Hurungwe is $12.7 \%$.

Extension services and urbanity were found to be the main determinants of exposure while access to credit, income, education, training and positive perception about modern technologies were found to increase the farmer's propensity to adopt modern agricultural technologies. But farmers with traditionally bonded parents were found to have a lower propensity to adopt modern agricultural technologies. These findings point to important policy implications. First, there is potential to improve agricultural technology adoption rates through improving farmers' exposure to technologies via various media such as radios, television and extension services among others. As revealed in this chapter, education and formal training also increase farmers' propensity to modernise their production systems.

Second, the results show that improved farmers' incomes and access to credit increase their propensity to adopt modern agricultural technologies. Access to credit has a significant effect on the farmer's decision to adopt modern technologies. The major implication of this finding is that financial inclusion for farmers is critical for modernising African agriculture. In many African countries, farmers face difficulties in accessing credit, leading to lack of investment in new agricultural technologies. This finding therefore suggests that financial inclusion through establishment of rural financial institutions can significantly aid modernisation of Zimbabwean agriculture. 
In conclusion, the findings generally point to the need for improving farmers' access to credit, reducing technological information asymmetry amongst farmers and intensifying education and agricultural training for farmers.

\section{References}

Akudugu, A. M., Guo, E., \& Dadzie, K. S. (2012). Adoption of Modern Agricultural Production Technologies by Farm Households in Ghana: What Factors Influence Their Decisions? Journal of Biology, Agriculture and Healthcare, 2(3), 1-13.

Anderson, C. R., \& Zeithaml, C. P. (1984). Stage of the Product Life Cycle, Business Strategy, and Business Performance. Academy of Management Journal, 27(1), 5-24.

Ayoola, B. J. (2012). Socio-Economic Determinants of the Adoption of Yam Minisett Technology in the Middle Belt Region of Nigeria. Journal of Agricultural Science, 4(6), 215-222.

Bayus, B. L. (1988). Accelerating the Durable Replacement Cycle with Marketing Mix Variables. Journal of Product Innovation Management, 5(3), 216-226.

Boko, M., Niang, I., Nyong, A., Vogel, C., Githeko, A., Medany, M., OsmanElasha, B., Tabo, R., \& Yanda, P. (2007). Africa. Climate Change 2007. Impacts, Adaptation and Vulnerability. Contribution of Working Group II to the Fourth Assessment Report of the Intergovernmental Panel on Climate Change, Parry, M. L., Canziani, O. F., Palutikof, J. P., van der Linden, P. J. \& Hanson, C. E. Eds., Cambridge University Press, Cambridge, 433-467.

Boniphace, N. S., Fengying, N., \& Chen, F. (2015). An Analysis of Smallholder Farmers' Socio-Economic Determinants for Inputs Use: A Case of Major Rice Producing Regions in Tanzania. Russian Journal of Agricultural and Socio-Economic Sciences, 38(2), 41-55.

De Janvry, A., \& Sadoulet, E. (2002). World Poverty and the Role of Agricultural Technology: Direct and Indirect Effects. Journal of Development Studies, 38(4), 1-26.

Diagne, A., \& Demont, M. (2007). Taking a New Look at Empirical Models of Adoption: Average Treatment Effect Estimation of Adoption Rate and Its Determinants. Agricultural Economics, 37(3), 201-210. 
Dimara, E., \& Skuras, D. (2003). Adoption of Agricultural Innovations as a TwoStage Partial Observability Process. Agricultural Economics, 28(3), 187-196.

Doss, C. R., Mwangi, W., Verkuijl, H., \& De Groote, H. (2003). Adoption of Maize and Wheat Technologies in Eastern Africa: A Synthesis of the Findings of 22 Case Studies. CIMMYT Economics Working Paper 3-7, Mexico, D.F, CIMMYT.

Duflo, E., Kremer, M., \& Robinson, J. (2008). How High Are Rates of Return to Fertilizer? Evidence from Field Experiments in Kenya. American Economic Review, 98(2), 482-488.

Fadare, A. O., Akerele, D., \& Toritseju, B. (2014). Factors Affecting Adoption Decisions of Maize Farmers in Nigeria. International Journal of Food and Agricultural Economics, 2(3), 45-54.

Feder, G., Just, E. R., \& Zilberman, D. (1985). Adoption of Agricultural Innovations in Developing Countries: A Survey. Economic Development and Cultural Change, 33(2), 255-298.

Foster, A. D., \& Rosenzweig, M. R. (2010). Microeconomics of Technology Adoption. Economic Growth Centre Discussion Paper No 984, Yale University, New York.

Gollin, D., Morris, M., \& Byerlee, D. (2005). Technology Adoption in Intensive Post-Green Revolution Systems. American Journal of Agricultural Economics, 87(5), 1310-1313.

Hailu, K. B., Abrha, K. B., \& Weldegiorgis, A. K. (2014). Adoption and Impact of Agricultural Technologies on Farm Income: Evidence from Southern Tigray, Northern Ethiopia. International Journal of Food and Agricultural Economics, 2(4), 91-106.

Harper, J. K., Rister, M. E., Mjelde, J. W., Drees, B. M., \& Way, M. O. (1990). Factors Affecting Adoption in Insect Management Technology. American Journal of Agricultural Economics, 72(4), 997-1005.

Kassie, M., Shireraw, B., \& Muricho, G. (2011). Agricultural Technology, Crop Income and Poverty Alleviation in Uganda. World Development, 39(10), 1784-1795.

Kijima, Y., Otsuka, K., \& Sserunkuuma, D. (2008). Assessing the Impact of NERICA on Income and Poverty in Central and Western Uganda. Agricultural Economics, 38(3), 327-337.

Lambkin, M., \& Day, G. S. (1989). Evolutionary Processes in Competitive Markets: Beyond the Product Life Cycle. Journal of Marketing, 53(3), 4-20. Langat, B. K., Ngéno, V. K., Nyangweso, P. M., Mutwol, M. J., Kipsat, M. J., Gohole, L., \& Yaninek, S. (2013). Drivers of Technology Adoption in a 
Subsistence Economy: The Case of Tissue Culture Bananas in Western Kenya. A Paper Presented at the 4th International Conference of the African Association of Agricultural Economists, September 22-25, 2013, Hammamet, Tunisia. Liu, Y., \& Wang, X. (2005). Technological Progress and Chinese Agricultural Growth in the 1990s. China Economic Review, 16(4), 419-440.

Matsumoto, T., Yamano, T., \& Sserunkuuma, D. (2013). Technology Adoption and Dissemination in Agriculture: Evidence from Sequential Intervention in Maize Production in Uganda. GRIPS Discussion Paper 13-14, National Graduate Institute for Policy Studies, Tokyo.

Mendola, M. (2007). Agricultural Technology Adoption and Poverty Reduction: A Propensity-Score Matching Analysis for Rural Bangladesh. Food Policy, 32(3), 372-393.

Midgley, D. F. (1977). Innovation and New Product Marketing. New York, NY: Halstead Press, John Wiley and Sons.

Mkandawire, R., \& Matlosa, K. (1994). Food Policy and Agriculture in Southern Africa. Harare: Southern African Research and Documentation Centre, SAPES Trust.

Muzari, W., Gatsi, W., \& Muvhunzi, S. (2012). The Impacts of Technology Adoption on Smallholder Agricultural Productivity in Sub-Saharan Africa: A Review. Journal of Sustainable Development, 5(8), 69-77.

Oster, E., \& Thornton, R. (2012). Determinants of Technology Adoption: Peer Effects in Menstrual Cup Take-up. Journal of the European Economic Association, 10(6), 1263-1293.

Pattanayak, S. K., Mercer, D. E., Sills, E., \& Yang, J. C. (2003). Taking Stock of Agroforestry Adoption Studies. Agroforestry Systems, 57(3), 173-186.

Pingali, P., Bigot, Y., \& Binswanger, H. P. (1987). Agricultural Mechanization and the Evolution of Farming Systems in Sub-Saharan Africa. Baltimore: World Bank, John Hopkins University Press.

Ravallion, M., \& Chen, S. (2004). How Have the World's Poorest Fared Since the 1980s? World Research Observer, 19(2), 141-170.

Reimer, J. J., \& Fisher, M. (2014). Are Modern Varieties Always Better? An Economic Analysis of Maize Varietal Selection. African Journal of Agricultural and Resource Economics, 9(4), 270-285.

Rogers, M. E. (1962). Diffusion of Innovations: Third Edition. New York: Macmillan Publishing Co Inc.

Simtowe, F., Kassie, M., Diagne, A., Silim, S., Muange, E., Asfaw, S., \& Shiferaw, B. (2011). Determinants of Agricultural Technology Adoption: The Case of Improved Pigeon Pea Varieties in Tanzania. Quarterly Journal of International Agriculture, 50(4), 325-345. 
Smale, M., Heisey, P. W., \& Leathers, H. D. (1995). Maize of the Ancestors and Modern Varieties: The Microeconomics of High-Yielding Variety Adoption in Malawi. Economic Development and Cultural Change, 43(2), 351-368.

Sunding, D., \& Zilberman, D. (2000). The Agricultural Innovation Process: Research and Technology Adoption in a Changing Agricultural Sector. Handbook of Agricultural Economics, 1, 207-261.

Suri, T. (2011). Selection and Comparative Advantage in Technology Adoption. Econometrica, 79(1), 159-209.

Uaiene, R. N., Arndt, C., \& Masters, W. A. (2009). Determinants of Agricultural Technology Adoption in Mozambique. National Directorate of Studies and Policy Analysis Discussion Paper No 67E, Ministry of Planning and Development, Mozambique.

Wooldridge, J. M. (2002). Econometric Analysis of Cross Section and Panel Data. Cambridge, MA: The MIT Press.

World Bank. (2008). Agriculture for Development: Overview. World Development Report, Washington, DC. Retrieved from www.worldbank.org/ INTWDR2008.

Xu, X., \& Jeffrey, S. R. (1998). Efficiency and Technical Progress in Traditional and Modern Agriculture: Evidence from Rice Production in China. Agricultural Economics, 18(1998), 157-167.

Zivanemoyo, J., \& Mukarati, J. (2013). Determinants of Choice of Crop Variety as Climate Change Adaptation Option in Arid Regions of Zimbabwe. Russian Journal of Agricultural and Socio-Economic Sciences, 15(3), 54-62.

Open Access This chapter is licensed under the terms of the Creative Commons Attribution 4.0 International License (http://creativecommons.org/licenses/ by/4.0/), which permits use, sharing, adaptation, distribution and reproduction in any medium or format, as long as you give appropriate credit to the original author(s) and the source, provide a link to the Creative Commons license and indicate if changes were made.

The images or other third party material in this chapter are included in the chapter's Creative Commons license, unless indicated otherwise in a credit line to the material. If material is not included in the chapter's Creative Commons license and your intended use is not permitted by statutory regulation or exceeds the permitted use, you will need to obtain permission directly from the copyright holder.

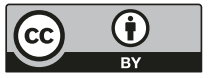

